\title{
Gambaran Pemanfaatan Upaya Kesehatan Bersumberdaya Masyarakat (UKBM) di Kecamatan Jatinangor
}

\author{
Nita Arisanti, ${ }^{1}$ Deni K Sunjaya, ${ }^{2}$ \\ ${ }^{1}$ Departemen Ilmu Kesehatan Masyarakat, Fakultas Kedokteran Universitas Padjadjaran
}

\begin{abstract}
Abstrak
Meningkatkan derajat kesehatan masyarakat bukan hanya tugas pemerintah saja tetapi diperlukan juga partisipasi masyarakat dengan memberdayakan masyarakat. Pemberdayaan masyarakat adalah upaya untuk memampukan masyarakat sehingga mampu mengenali dan menyelesaikan permasalahan.Berbagai upaya kesehatan yang bersumberdaya masyarakat telah dikembangkan di Indonesia seperti Pos Pelayanan Terpadu (Posyandu), Pondok Bersalin Desa (Polindes), Pos Kesehatan Desa (Poskesdes), pos obat desa POD), dana sehat, dll, tetapi pemanfaaranya masih kurang. Tujuan penelitian ini adalah untuk mengetahui penggunaan upaya kesehatan bersumberdaya masyarakat di Kecamatan Jatinangor, Sumedang, Indonesia. Metode penelitian ini adalah survei deskriptif dengan menggunakankuesioneryang disebarkankepada 820responden. Datadisajikandalambentuktabeldistribusifrekuensi. Hasil penelitian ini menunjukkan bahwa hanya sekitar $46 \%$ yang memanfaatkan posyandu. Alasan mereka tidak memanfaatkannya adalah tidak perlu. Hanya $28,5 \%$ penduduk yang memanfaatkan polindes. Alasan tidak memanfatkannya adalah sebagian besar merasa tidak membutuhkan dan sebagian besar penduduk menggunakan polindes untuk mendapatkan pengobatan $(53,3 \%)$ bukan pemeriksaan kehamilan dan persalinan. Tidak ada Pos Obat Desa dan Pos Kesehatan Desa yang dikembangkan di Kecamatan Jatinangor. Perlu adanya revitalisasi untuk UKBM, sehingga UKBM dapat menjadi ujung tombak dalam meningkatkan status kesehatan masyarakat.
\end{abstract}

Kata kunci: bersumberdaya masyarakat, penggunaan, upaya kesehatan

\section{Utilization of Community Based Health Services in Jatinangor}

\begin{abstract}
Health status of the community cannot be achieved by government only. Enabling community in health means taking action in partnership with individuals or groups to empower them through mobilization of human and material resources. Government of Indonesia had developed many programs in health service to empower community such as Integrated Health Center (Pos Pelayanan Terpadu, Posyandu), Village Delivery Center (Pondok Bersalin Desa, Polindes), Village Drugs Center (Pos Obat Desa) and Village Health Insurance (Dana Sehat). In fact, the utilization of these health servicewas still not optimal. The objective of this study was to determine the utilization of community-based health services in Jatinangor, Indonesia. The study method was descriptive by giving questionnaires to 820 respondents. The result is presented in distribution frequency table. The result of this study showed only $46 \%$ respondents utilized Posyandu. Most of respondent did not find any advantages from Posyandu. The reason for utilizing Posyandu was for weighing. Only 28.5\% respondents utilized Polindes. Most of them did not utilize Polindes because they did not need. From respondents who utilize Polindes, the reason was to seek medical care (53.3\%). There are no Pos Obat Desa and Dana Sehat in Jatinangor. Revitalizing community-based health services are necessary to increase community empowerment in order to achieve better health status.
\end{abstract}

Key words: community-based health services,community empowerment, utilization

\footnotetext{
Korespondensi :

Nita Arisanti,dr., M.Sc-FM

Departemen Ilmu Kesehatan Masyarakat Fakultas Kedokteran Unpad

Jl. Eijkman No. 38 Bandung

e-mail: nitarisanti@yahoo.com
} 


\section{Pendahuluan}

Kesehatan adalah suatu masalah yang kompleks yang merupakan kompilasi dari berbagai masalah. Menurut Hendrik L.Blum, pengaruh terbesar adalah lingkungan dan sekarang mulai bergeser menjadiperilaku. Pelayanan kesehatan merupakan faktor ketiga yang memengaruhi derajat kesehatan masyarakat. Peran penting pelayanan kesehatan dalam menentukan status kesehatan masyarakat harus diimbangi dengan ketersediaan fasilitas tersebut yang harus diupayakan oleh pemerintah dan masyarakat. Ketersediaan fasilitas dipengaruhi oleh lokasi, keterjangkauan dan pemberi pelayanan. ${ }^{1}$ Selain lokasi dan tenaga kesehatan, ketersediaan fasilitas pelayanan kesehatan juga dipengaruhi oleh informasi dan motivasi masyarakat untuk mendatangi fasilitas dalam memperoleh pelayanan serta program pelayanan kesehatan itu sendiri. Di masyarakat terdapat beberapa pelayanan kesehatan baik primer, sekunder maupun tersier. Upaya Kesehatan Bersumberdaya Masyarakat (UKBM) merupakan bentuk fasilitas pelayanan kesehatan yang dikelola oleh masyarakat.Beberapa bentuk UKBM yang dikenal adalah Posyandu (Pos Pelayanan Terpadu), Polindes (Pondok Bersalin desa) dan Desa Siaga. Keberhasilan pelaksanaan UKBM ini tidak terlepas dari peran masyarakat sebagai pelaksana dan penerima pelayanan kesehatan, sehingga perlu dilakukan kajian mengenai penggunaan UKBM oleh masyarakat.

Kecamatan Jatinangor merupakan kawasan andalan Kabupaten Sumedang. Dengan terdapatnya tiga perguruan tinggi di Jatinangor, pertumbuhan penduduk di Jatinangor pun semakin pesat. Hal ini berdampak pada berkembangnya pelayanan kesehatan swasta di kecamatan tersebut, sehingga masyarakat mempunyai pilihan untuk mendapatkan pelayanan kesehatan. Melihat kecenderungan tersebut diperlukan kajian untuk melihat penggunaan UKBM di Jatinangor. Tujuan penelitian ini adalah untuk mengetahui gambaran pemanfaatan Upaya Kesehatan Bersumberdaya Masyarakat di Kecamatan Jatinangor, Sumedang, Indonesia.

\section{Metode}

Penelitian ini dilakukan di Kecamatan Jatinangor. Secara kewilayahan Kecamatan Jatinangor mencakup 12 desa, 128 Rukun Warga (RW) dan 464 Rukun Tetangga (RT). Disain penelitian ini adalah deskriptif dengan melakukan survey. Populasi pada kegiatan ini adalah masyarakat di Kecamatan Jatinangor. Perhitungan sampel dilakukan dengan menggunakan rumus. Dengan confidence interval $95 \%, \mathrm{P}=0.5$ dan $\Delta=0.1$, maka didapatkanjumlahsampelpenelitianiniadalah 820 . Kriteria inklusi adalah warga Kecamatan Jatinangor baik warga asli maupun pendatang dan kriteria eksklusinya tidak bersedia di wawancara. Metode pengambilan sampel (sampling) yang digunakanadalah three-stage household sampling. Yang berlaku sebagai primary, secondary dan ultimate sampling unit secara berturut-turut adalah desa, RW dan RT. Alokasi sampel dilakukan secara proportional to size, berdasarkan jumlah KK yang terdapat di desa.Kemudian di tiap klaster dipilih kepala keluarga secara random.

Data primer dalam kajian ini diperoleh melalui survey dengan memberikan kuesioner kepada kepala keluarga di setiap klaster dan daftar isian untuk ketua rukun warga (RW) dan kepala desa. Sedangkan data sekunder diperoleh dari data umum dan data kesehatan di Kecamatan Jatinangor, Puskesmas Jatinangor, kelurahan di wilayah Kecamatan Jatinangor. Data dipresentasikan dalam bentuk distribusi frekuensi.

\section{Hasil}

Berdasarkan studi dokumen dan daftar tilik diketahui bahwa dari 128 RW di Kecamatan Jatinangor, hanya terdapat 70 posyandu. Jika dilihat standarnya 1 RW mempunyai 1 Posyandu, maka Kecamatan Jatinangor masih kekurangan Posyandu. ${ }^{2}$ Terdapat 343 kader aktif, jika menurut pedoman pelaksanaan posyadu, 1 posyandu minimal memiliki 5 kader aktif maka jumlah kader di Kecamatan Jatinangor masih kurang untuk 70 Posyandu.Terdapat 8 Polindes. Empat desa yang tidak mempunyai Polindes yaitu Desa Hegarmanah, Desa Sayang, Desa Jatiroke dan Desa Mekargalih. Data ini tidak sesuai dengan data kecamatan yang menyebutkan terdapat 12 Polindes. Di masyarakat Jatinangor terdapat 4 dana sehat dengan 1648 KK sasaran. Dengan jumlah penduduk 87.776, perlu digiatkan lagi partisipasi masyarakat untuk membentuk dana sehat.

Berdasarkan pengambilan kuesioner diketahui bahwa pemanfaatan UKBM di Kecamatan Jatinangor didapatkan hanya sekitar $46 \%$ yang memanfaatkan posyandu untuk mendapatkan pelayanan kesehatan. Alasan mereka tidak memanfaatkannya adalah tidak perlu. Dari kegiatan - kegiatan yang ada di posyandu, penimbangan merupakan kegiatan yang sering didapatkan oleh penduduk. Hasil ini sesuai dengan tujuan didirikannya Posyandu yaitu meningkatnya cakupan dan jangkauan pelayanan kesehatan dasar, terutama yang berkaitan dengan penurunan AKI, AKB dan AKABA. Penimbangan merupakan kegiatan. 


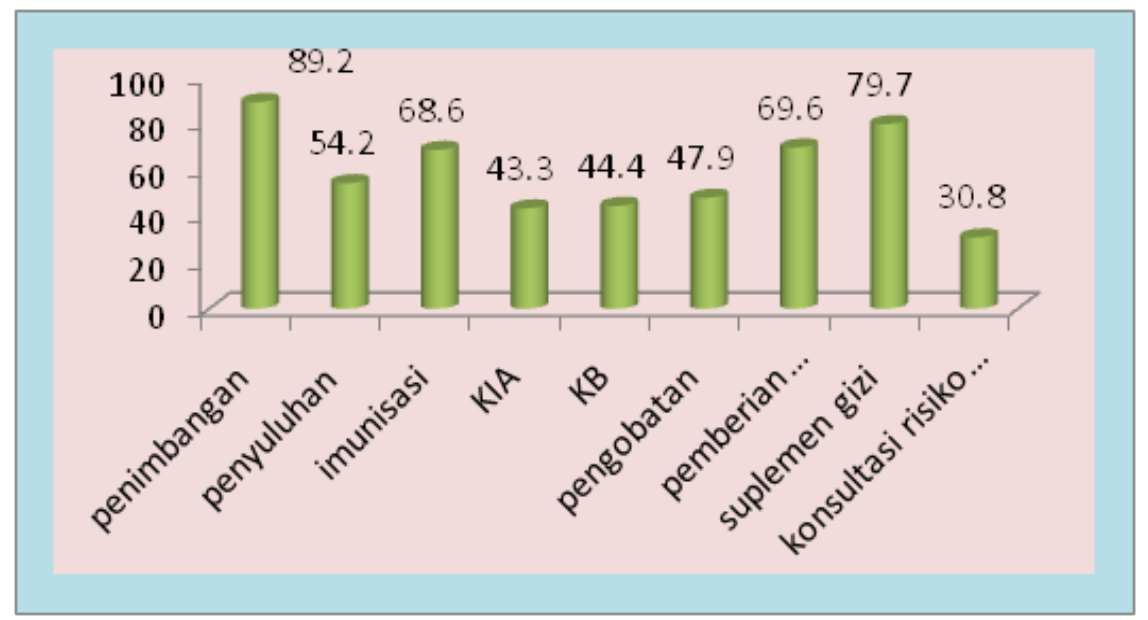

\section{Gambar 1. Gambaran Pelayanan Kesehatan yang Diterima di Posyandu}

yang diperlukan untuk memantau status gizi bayi, balita dan ibu hamil Untuk polindes, hanya $28,5 \%$ penduduk yang memanfaatkannya. Alasan tidak memanfatkannya adalah sebagian besar merasa tidak membutuhkannya. Hal ini perlu dicermati karena angka kematian ibu dan angka kematian bayi di Jawa Barat masih tinggi, padahal maksud didirikannya polindes adalah sebagai upaya untuk memperluas jangkauan, meningkatkan mutu dan mendekatkan pelayanan KIA termasuk $\mathrm{KB} \cdot{ }^{3}$ Perlu adanya pendidikan kesehatan tentang kegunaan polindes ini, karena dari kuesioner yang disebarkan sebagian besar penduduk menggunakan polindes untuk mendapatkan pengobatan $(53,3 \%)$, padahal polindes digunakan untuk pelayanan kehamilan dan persalinan.Untuk Pos Obat Desa(POD), hampir semua penduduk tidak memanfaatkannya karena tidak ada POD.

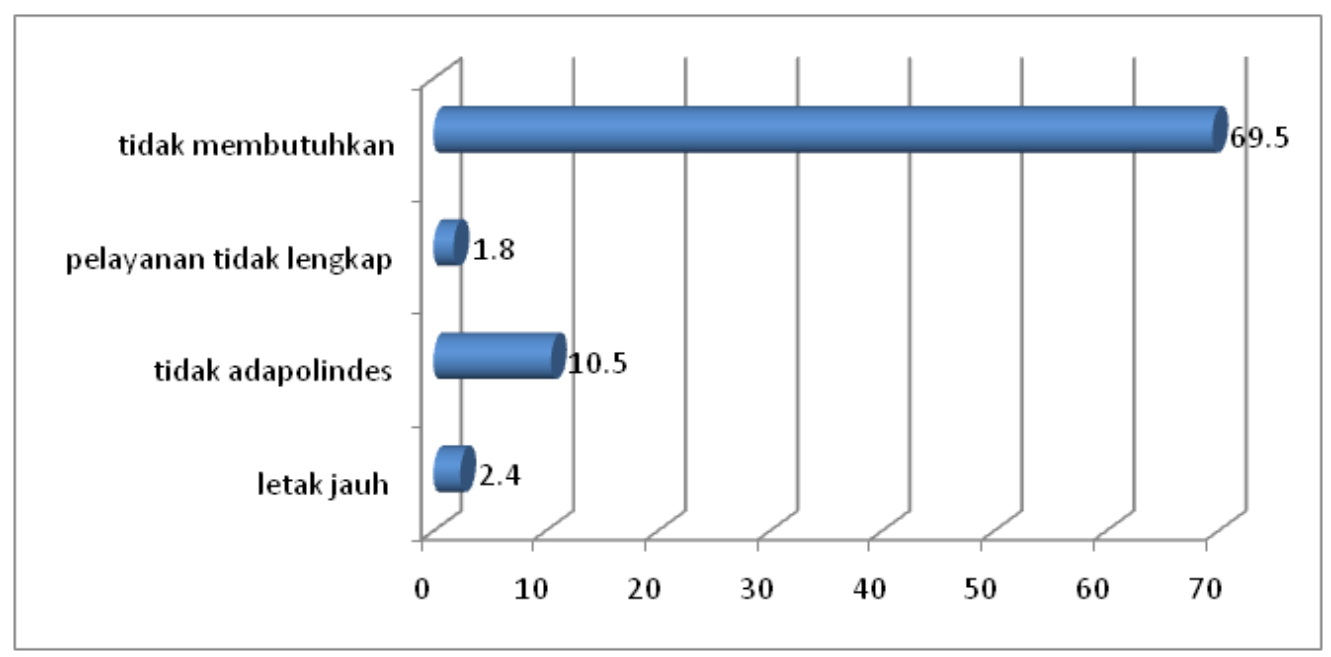

Gambar 2. Alasan Masyarakat Tidak Memanfaatkan Polindes 


\section{Pembahasan}

Pos Pelayanan Terpadu (Posyandu) merupakan salah satu bentuk UKBM yang dikelola dan diselenggarakanuntuk dan oleh bersama masyarakat, guna penyelenggaraan pembangunan kesehatan dalam memberdayakan masyarakat dan memberikan kemudahan kepada masyarakat dalam memperoleh pelayanan kesehatan. Berdasarkan Standar Pelayanan Minimal (SPM) bidang kesehatan untuk Kabupaten/Kota Tahun 2008, indikator baik tidaknya pemanfaatan posyandu dinilai dari cakupan kunjungan secara kumulatif yang harus mencapai 90\% atau lebih, sehingga dapat dianggap baik, sedangkan kurang dari 90\% dianggap belum baik pemanfaatannya. ${ }^{2}$ Penelitian ini sejalan dangan penelitian nasional yang menyebutkan bahwa di Indonesia jumlah kunjungan ibu yang membawa balita ke posyandu hanya sebesar 27,8\% dari 224.000 kegiatan Posyandu yang ada di Indonesia, sehingga dapat dikatakan pemanfaatan posyandu oleh masyarakat belum optimal. Data terakhir menunjukkan hanya sekitar $35 \%$ masyarakat yang menggunakan posyandu. ${ }^{2}$

Pemanfaatan pelayananan kesehatan bergantung pada faktor-faktor internal dan eksternal antara lain sosiodemografis, tingkat pendidikan, kepercayaan dan praktik kultural, diskriminasi jender, status perempuan, kondisi lingkungan, sistem politik dan ekonomi, pola penyakit serta sistem pelayanan kesehatan. Salah satu faktor internal yang memengaruhi adalah pengetahuan. Jika masyarakat telah mendapatkan informasi dan pengetahuan tentang suatu program, masyarakat akan cenderung lebih berpartisipasi. Beberapa penelitian menunjukkan bahwa tingkat pengetahuan responden tentang posyandu lansia yang baik akan meningkatkan pemanfaatan layanan posyandu tersebut. ${ }^{4}$ Selain pengetahuan, faktor eksternal yang memengaruhi pemanfaatan pelayanan kesehatan adalah dukungan sosial. Penelitian di India menyebutkan bahwa keterlibatan keluarga terutama keluarga terdekat seperti suami akan meningkatkan partisipasi masyarakat yaitu ibu dalam memanfaatkan program persalinan yang berbasis masyarakat. ${ }^{5}$

Faktor lain yang dapat memengaruhi pemanfaatan pelayanan adalah pelayanan yang diberikan di fasilitas tersebut. Penelitian lain mendapatkan bahwa masyarakat yang tidak mengetahui program di posyandu lansia berpendapat bahwa kegiatan tersebut kurang bermanfaat. Masyarakat berpendapat bahwa program pencegahan penyakit yang diberikan di posyandu lansia kurang baik dibandingkan dengan pelayanan pengobatan yang dilakukan dokter. Hal ini terjadi karena kurangnyasosialisasi tentang posyandu lansia ke masyarakat. ${ }^{4}$ Penelitian lain menunjukkan bahwa pengetahuan masyarakat yang baik mengenai program pelayanan kesehatan berbasis masyarakat akan meningkatkan pemanfaatan pelayanan kesehatan tersebut. Penelitian ini menunjukkan keterlibatan yang tinggi dari ibu yang mengetahui program pelayanan yang diberikan oleh program keluarga berencana berbasis masyarakat. ${ }^{6}$ Penelitian lain mendapatkan bahwa rendahnya pemanfaatan UKBM disebabkan oleh kurangnya sosialisasi tujuan, sasaran dan kegiatan di masyarakat yang berdampak pada rendahnyapengetahuan akan hal tersebut. Kesadaran masyarakat yang baik tentang program berhubungan dengan penggunaan pelayanan.Hal ini ditemukan lebih bermakna jika pelayanan diselenggarakan di daerah pedesaan. ${ }^{7}$

Penelitian lain menyebutkan bahwa pemanfaatan pelavanan kesehatan oleh masyarakat di Posyandu berkaitan dengan aktifitas kader dan keberadaan posvandu di masyarakat. ${ }^{8-10}$ Agar kader mau bekerja dengan baik dan aktif perlu diberi penghargaan dengan mendapatkan pelayanan kesehatan gratis dan pelatihan..$^{910}$ Jika dilihat manfaat UKBM seperti posyandu, sangat disayangkan jika posyandu tidak dimanfaatkan secara optimal. Penelitian menyebutkan bahwa rumah tangga yang memanfaatkan pelavanan kesehatan, lebih banvak balitanya berstatus gizi baik dan angka kesakitan rendah dibandingkan dengan yang tidak memanfaatkan pelayanankesehatan. ${ }^{8}$

Keterbatasan penelitian ini antara lain adalah tidak dilakukan eksplorasi lebih lanjut mengenai faktor-faktor yang memengaruhi pemanfaatan UKBM di masyarakat. Hasil penelitian ini menunjukkan bahwa hanya sekitar $46 \%$ yang memanfaatkan memanfaatkan polindes. Tidak ada pos obat desa dan pos kesehatan desa yang dikembangkan di Kecamatan Jatinangor ini. Perlu adanya revitalisasi untuk UKBM, sehingga UKBM dapat menjadi ujung tombak dalam meningkatkan status kesehatan masyarakat. Bentuk revitalisasi yang dapat dilakukan adalah perbaikan sarana-prasarana, meningkatkan kompetensi sumber daya manusia, memperbaiki Standar Operasional Prosedur. Selain itu juga diperlukan penelitian untuk mencari faktor yang memengaruhi pemanfaatan UKBM di Jatinangor.

\section{Daftar Pustaka}

1. Detels R, Breslow L, Editors. Oxford Textbook Of Public Health. 4th Ed. New York: Oxford University Press; 2002. 
2. Kementerian Kesehatan RI. Pedoman Umum Pengelolaan Posyandu. Jakarta: Kementrian Kesehatan Republik Indonesia. 2011.

3. Departemen Kesehatan Republik Indonesia. Pedoman Pondok Bersalin. Jakarta : Departemen Kesehatan Republik Indonesia. 1994.

4. Mulyadi.Pemanfaatan Posyandu Lansia. Jurnal Kesehatan Masyarakat Nasional. 2009;3(5): 224-28.

5. Fotso JC, Higgins-Steele A, MohantyS. Male engagement as a strategy to improveutilization and community-based delivery ofmaternal, newborn and child health services:evidence from an intervention in Odisha, India. BMC Health Services Research. 2015; 15(Suppl 1):S5: 2-10.

6. Yitaya M, Berhane Y, Worku A, Kebede Y. The community-based Health Extension Program significantly improved contraceptiv e utilization in West Gojjam Zone, Ethiopia. Journal of
Multidisciplinary Healthcare. 2014; 7:201-8.

7. Kakietek J, etal. It takes a village: Communitybased organizations and the availability and utilization of HIV/AIDS-related services in Nigeria. AIDS Care. 2013;25(1):78-87.

8. Hidayat TS, Jahari, AB. Perilaku Pemanfaatan Posyandu HubungannyaDengan Status Gizi Dan Morbjditas Balitabul. Penelit. Kesehat. 2012;40(1):1-10.

9. Uzondu CA, Doctor HV, Findley SE,Afenyadu GY,Ager A. Female Health Workers at the Doorstep: A Pilot ofCommunity-Based Maternal, Newborn, and Child HealthService Delivery in Northern Nigeria. Global Health: Science and Practice.2015; 3(1):97-108. 10. Afework MF, Admassu K, Mekonnen A, Hagos S, Asegid M, Ahmed S. Effect of an innovative community based healthprogram on maternal health service utilization innorth and south central Ethiopia: a communitybased cross sectional study. Reproductive Health. 2014;11(28):1-9. 